\title{
PIWI-like protein, HIWI2 is aberrantly expressed in retinoblastoma cells and affects cell-cycle potentially through OTX2
}

\author{
Suganya Sivagurunathan ${ }^{1,2}$, Jayamuruga Pandian Arunachalam ${ }^{3,4}$ and Subbulakshmi Chidambaram ${ }^{1,5^{*}}$ (D)
}

\author{
* Correspondence: \\ csubbulakshmi@gmail.com \\ ${ }^{1}$ RS Mehta Jain Department of \\ Biochemistry and Cell Biology, \\ Vision Research Foundation, \\ Chennai, India \\ ${ }^{5}$ Department of Biochemistry and \\ Molecular Biology, Pondicherry \\ University, Puducherry, India \\ Full list of author information is \\ available at the end of the article
}

\begin{abstract}
Retinoblastoma (RB), a childhood cancer, is caused by biallelic mutation of the RB1 gene, but its development is not clearly understood. Furthermore, the presence of a cancer stem cell subpopulation in RB might impact its treatment. PIWI protein, known for its role in stem cell self-renewal, is aberrantly expressed in cancers. We examined the role of the PIWI-like protein HIWI2 in RB and its effect on the stem cell markers in cells of the RB line, Y79. The expression of HIVI2 is significantly increased in Y79 compared with its level in HeLa and ARPE19 cells. The stem cell markers Oct-3/4, Nanog and Sox-2 were not altered upon HIWI2 knockdown in Y79 cells. Interestingly, OTX2 was significantly downregulated in the absence of HIWI2. Otx2 transcripts also decreased in HIVI2-silenced Y79 and ARPE19 cells. Moreover, silencing HIWI2 in Y79 accumulated the cells at G2-M phase and reduced the levels of proliferating cell nuclear antigen (PCNA) and the tumor suppressor, p16. Our results demonstrate that HIVI2 is aberrantly expressed in Y79 cells and silencing of HIVI2 downregulates OTX2, suggesting that HIWI2 might play a role in the progression of RB.
\end{abstract}

Keywords: Y79, ARPE19, PCNA, Stem cell markers

\section{Introduction}

Retinoblastoma (RB), the most common ocular cancer, mainly occurs due to the biallelic mutation of the $R B 1$ gene on chromosome 13 [1]. The "two-hit" hypothesis suggests that two mutational events are needed in $R B 1$ for RB to develop [2]. Besides the inactivation of $R B 1$, epigenetic changes are also involved in the tumor formation [3, 4].

Although significant advances have been made in recent years, the mechanism behind the onset and progression of RB is still not well understood. Because many factors are involved in its development, RB treatment is challenging. Current therapies like enucleation, brachytheraphy and laser photocoagulation have devastating effects [5], so better therapies with less disease morbidity are essential. Designing such therapies requires the identification of endogenous proteins that can be modulated to curb the progression of RB.

PIWI-like proteins are essential for stem cell self-renewal [6]. They bind with small non-coding RNAs called piwi-interacting RNAs (piRNAs) [7]. These PIWI-piRNA complexes mainly function in silencing transposable elements to protect the genomic integrity of germline cells [8]. HIWI, HILI, PIWIL3 and HIWI2 are the four members

\section{( Biomed Central}

(c) The Author(s). 2017 Open Access This article is distributed under the terms of the Creative Commons Attribution 4.0 International License (http://creativecommons.org/licenses/by/4.0/), which permits unrestricted use, distribution, and reproduction in any medium, provided you give appropriate credit to the original author(s) and the source, provide a link to the Creative Commons license, and indicate if changes were made. The Creative Commons Public Domain Dedication waiver (http://creativecommons.org/ publicdomain/zero/1.0/) applies to the data made available in this article, unless otherwise stated. 
of the PIWI family in humans [9]. Besides their role in stem cell self-renewal and transposon silencing in germline cells, they are important in epigenetic silencing [10].

We recently demonstrated the function of HIWI2 in somatic cells, where it plays a role in maintaining the integrity of retinal pigment epithelial cells by regulating the Akt/GSK3 pathway [11]. Other recent reports have shown the abnormal expression of PIWI-like proteins in various cancers, where they are known to promote cell division, resist apoptosis and facilitate cell invasion and migration [12]. PIWI-like proteins are known to influence cancer cells through modulation of STAT3, TGF $\beta$, FGF, MAPKERK and p53 signalling pathways [13, 14]. PIWI-like proteins and piRNAs are also suggested as novel prognostic biomarkers in breast cancer [15] and gastric cancer [16]. Although there has been considerable study of the role of PIWI-like proteins in cancer, their involvement in RB remains unexplored.

Recent studies suggest cancer stem cells as one of the reason for the resistance and recurrence of the tumor [17], so the genes responsible for stemness are candidates for therapy [18]. Aberrant expression of PIWI-like proteins in cancerous conditions indicate their role in the stem cell characteristics of RB.

In this study, we examined the role of HIWI2 in RB and its effect on the stem cell characteristics of RB cells. Our results show that HIWI2 is highly expressed in Y79 cells and affects cell cycle, possibly through OTX2.

\section{Experimental procedures}

\section{Cell culture}

Y79 cells were cultured using RPMI 1640 (GE Healthcare Life Sciences) supplemented with $10 \%(v / v)$ heat-inactivated fetal bovine serum (FBS; Invitrogen). The cells were maintained in $5 \% \mathrm{CO}_{2}$ at $37{ }^{\circ} \mathrm{C}$ with antibiotics and antimycotics (Thermo Fisher Scientific). ARPE19 cells were maintained in DMEM-F12 (Sigma-Aldrich) and $14.2 \mathrm{mM}$ sodium bicarbonate and HeLa cells in DMEM-HG (HIMEDIA) with 10\% ( $v / \mathrm{v})$ heatinactivated FBS under the same conditions.

\section{RNAi experiments}

The cells were grown to confluency and $2 \times 10^{5}$ cells were seeded in 6-well plates. DsiRNA specific for HIWI2 (sense strand 5'-GCAUCACUAGAUGGACAAUCCAAGA-3'; antisense3'-ACCGUAGUGAUCUACCUGUUAGGUUCU-5'; Integrated DNA Technologies) was transfected to the cells using Lipofectamine RNAiMax (Invitrogen) as per the manufacturer's protocol. Protein lysates were obtained by lysing the cells $48 \mathrm{~h}$ post transfection.

\section{Real-time PCR}

RNA was isolated from cells transfected with scrambled siRNA (Si-Control) and HIWI2 siRNA (Si-HIWI2) $48 \mathrm{~h}$ post transfection using TRI reagent (Sigma-Aldrich). $1 \mu \mathrm{g}$ of RNA was converted to cDNA using an iScript kit (Biorad). The transcript levels of Otx2 and HIWI2 were determined using SYBR green assays (Roche Diagnostics) via real-time PCR (Roche Diagnostics). $18 S$ rRNA and $\beta$-actin were used as the endogenous controls. The gene expression of the transcripts was quantified using the relative quantification method. 


\section{Western blot}

Cells were lysed using radio immunoprecipitation assay (RIPA) buffer consisting of $150 \mathrm{mM} \mathrm{NaCl}, 0.1 \%$ TritonX-100, 0.5\% sodium deoxycholate, 0.1\% SDS and $50 \mathrm{mM}$ Tris ( $\mathrm{pH} 8.0$ ) with protease inhibitors $(1 \mathrm{mmol} / \mathrm{l}$ dithiothreitol, $0.5 \mathrm{mmol} / \mathrm{l}$ phenylmethylsulfonyl fluoride, $1 \mathrm{mg} / \mathrm{ml}$ leupeptin, $10 \mathrm{mmol} / \mathrm{l}$ p-nitrophenylphosphate, $10 \mathrm{mmol} / \mathrm{l} \mathrm{h}$-glycerol phosphate). Then, the cells were sonicated. The lysate was centrifuged at 10,000 rpm for $10 \mathrm{~min}$, the protein concentration was estimated using BCA protein assay reagent (Thermo Scientific), and $50 \mu \mathrm{g}$ of protein was resolved on SDSPAGE gel and electrotransferred to nitrocellulose membrane (GE Healthcare). The blots were incubated in blocking buffer ( $5 \%$ skimmed milk powder in Tris-buffered saline) for $1 \mathrm{~h}$ and were probed against HIWI2 (Pierce), OTX2 (Abcam), p16 (PathnSitu Biotechnologies) and PCNA (Cell Signaling Technology) primary antibodies in a 1:1000 dilution of blocking buffer. Anti-rabbit and anti-mouse secondary antibodies (Santa Cruz Biotechnology) were used in a 1:10,000 dilution. The blots were then developed with FluorChem FC3 (Protein Simple) using ECL reagent (GE Healthcare).

\section{Proteome profiler array}

Proteins that were altered after HIWI2 silencing were screened using the Human Pluripotent Stem Cell Array Kit (R\&D Systems). Protein lysates were prepared according to manufacturer's protocol and $200 \mu \mathrm{g}$ of protein was used for the array. The array was imaged and quantified using the Alpha View software (ProteinSimple). Fold changes in the protein expression levels are represented.

\section{Cell cycle analysis}

HIWI2-silenced Y79 cells were washed twice with phosphate buffered saline (PBS) by centrifuging at $1500 \mathrm{rpm}$ for $5 \mathrm{~min}$. The washed cells were fixed with $30 \%$ ice-cold ethanol via incubation for $30 \mathrm{~min}$ on ice. After fixation, the cells were again washed with PBS by centrifuging at $3000 \mathrm{rpm}$ for $5 \mathrm{~min}$. Cells were treated with $0.5 \mathrm{mg} / \mathrm{ml}$ RNase A (Sigma Aldrich) by incubating at $37{ }^{\circ} \mathrm{C}$ for $20 \mathrm{~min}$. They were then stained with $50 \mu \mathrm{g} / \mathrm{ml}$ propidium iodide (Sigma Aldrich) for $30 \mathrm{~min}$ at $4{ }^{\circ} \mathrm{C}$. The stained cells were analysed using FACSCalibur (Beckton Dickinson). A total of 20,000 events were collected for each sample.

\section{Statistical analysis}

Student's $t$-test was used to comparatively analyse the mean obtained from three independent experiments. The difference between the samples were considered to be statistically significant when the $p$-values were $p<0.05$.

\section{Results}

\section{The expression of HIWI2 is elevated in Y79 cells}

The expression of the HIWI2 transcript was studied using quantitative PCR in human retinal pigment epithelial cells (ARPE19), human cervical epithelial carcinoma cells (HeLa) and human RB cells (Y79). The expression of HIWI2 was 1.38-fold higher in HeLa than in ARPE19 (Fig. 1a). Interestingly, Y79 showed a 24.86-fold increase when HeLa is considered (Fig. 1b). 


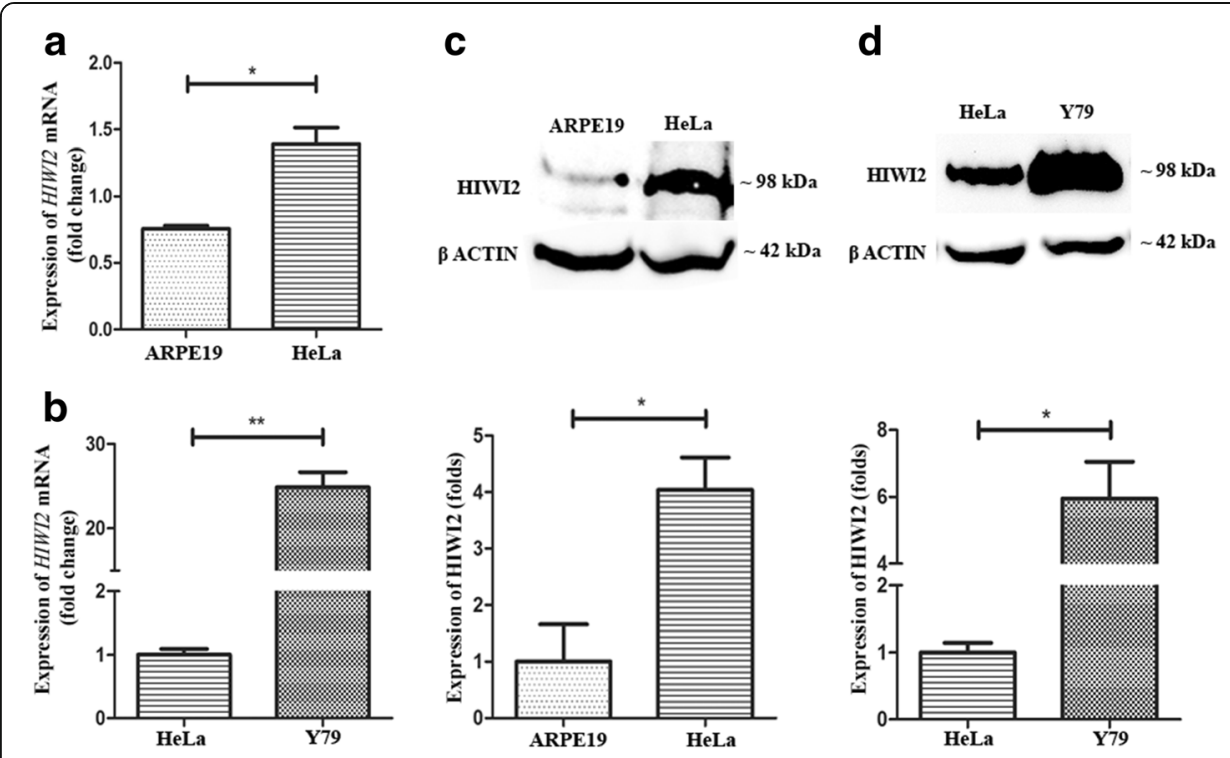

Fig. $1 \mathrm{HIWI} 2$ is aberrantly expressed in retinoblastoma. $\mathbf{a}, \mathbf{b}$ - Real-time PCR shows the expression of HIWI2 transcripts in ARPE19, HeLa and Y79 cell lines. $\beta$-actin was used for normalization and fold changes in expression are indicated. $\mathbf{c}$ - Western blot shows the expression of HIWI2 in protein lysates of ARPE19 and HeLa. $\beta$-ACTIN was used for normalization and the fold changes are indicated. The bar graph represents the quantification of the western blot image representing the fold change in the expression of HIWI2 in ARPE19 and HeLa cells. d - Western blot shows the expression of HIWI2 in protein lysates of HeLa and Y79 cell lines. $\beta$-ACTIN was used for normalization and the fold changes are indicated. The bar graph represents the quantification of the western blot image representing the fold change of HIWI2 in HeLa and Y79 cell lines. Student's t-test was used for statistical analysis. ${ }^{*} p<0.05$ and ${ }^{* *} p<0.01$ were considered statistically significant

Western blot analysis showed that HIWI2 expression was 4-fold higher in HeLa than in ARPE19 (Fig. 1C) and there was 5.9-fold increase in HIWI2 expression in Y79 over HeLa (Fig. 1d). Clearly, HIWI2 is aberrantly expressed in Y79 cells at both the mRNA and protein levels.

\section{OTX2 is downregulated upon HIWI2 knockdown}

To discern the role of HIWI2 on stem cell markers of RB, HIWI2 was silenced in Y79 cells using DsiRNA (Fig. 2a). The cell lysates were screened using a Human Pluripotent Stem Cell Array (Fig. 2b). Interestingly, OTX2, an eye field specification transcription factor, and VEGFR2 were significantly downregulated in Si-HIWI2 cells (Fig. 2b and c). However, Oct-3/4, Nanog and Sox-2 did not show any significant changes in HIWI2silenced Y79 cells (Fig. $2 b$ and c).

HIWI2 has been reported to affect the invasive properties of HeLa [19], which might be attributed to VEGF and its receptors. Since OTX2 plays crucial roles in the development of the eye [20], we further evaluated the relationship between OTX2 and HIWI2. OTX2 expression in Si-HIWI2 cells decreased 1.87-fold, which further validated the stem cell array data (Fig. 2d). The mRNA expression of Otx2 in HIWI2-silenced cells was also in accordance with the results obtained in the array (Fig. 2e). The expression of Otx2 in SiHIWI2 cells was 2.94-fold lower than in Si-Control cells (Fig. 2e). Since knockout of otx2 has shown to affect retinal pigment epithelial function [21], the expression of Otx2 transcripts were also evaluated in ARPE19. On silencing HIWI2, Otx2 was found to be 2.02- 

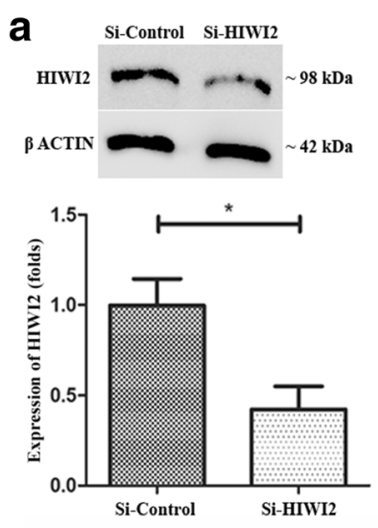

C

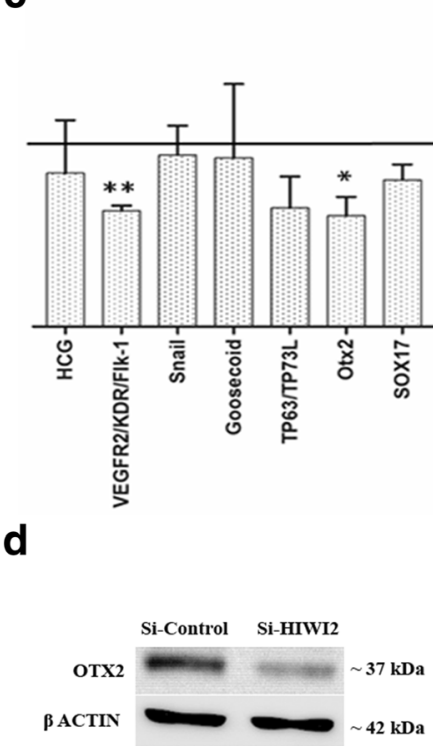

b

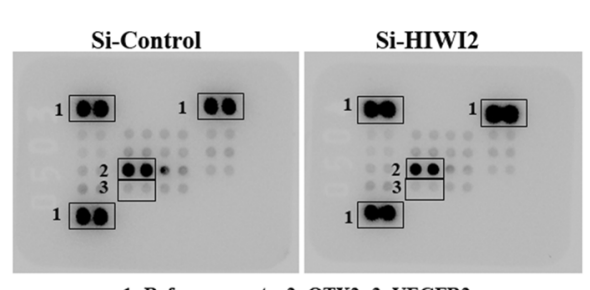

1- Reference spots; 2- OTX2; 3- VEGFR2

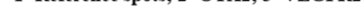


fold reduced (Fig. 2f). Thus, the absence of HIWI2 in Y79 cells specifically downregulated OTX2 and showed no significant effect on other stem cell genes tested.

\section{Suppression of HIWI2 decreases proliferation of Y79 cells}

Since OTX2 directly regulates cell cycle genes [22], we monitored the effects of HIWI2 on the cell cycle distribution of Y79 cells. Cell cycle analysis by flow cytometry indicated that suppression of HIWI2 affects the cell cycle in Y79 cells (Fig. 3a). HIWI2-silenced Y79 cells were arrested at G2-M phase (Fig. 3b). The expression of PCNA significantly decreased by $43 \%$ in Si-HIWI2 cells, reflecting the effect of HIWI2 on the proliferation of Y79 cells (Fig. 3c).

Since HIWI2 is known to regulate the expression of p16 [10], a cell cycle regulator, we evaluated p16 levels in Si-HIWI2 cells. Silencing HIWI2 reduces the expression of p16 (Fig. 3d). These results indicate that HIWI2 alters the cell cycle distribution of Y79 cells, and therefore could affect proliferation.

\section{Discussion}

This study reports the first evidence of elevated expression of HIWI2 in Y79 cells and a possible functional relationship with OTX2. Furthermore, a projected role of HIWI2 in

a
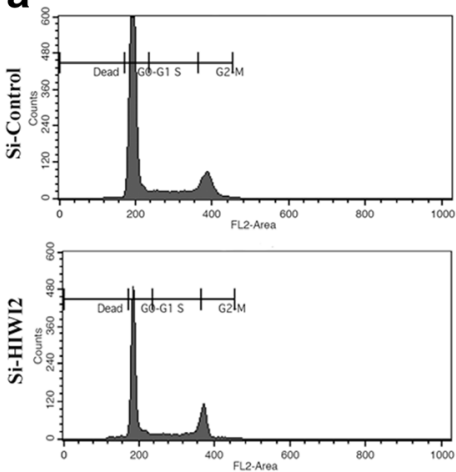

C
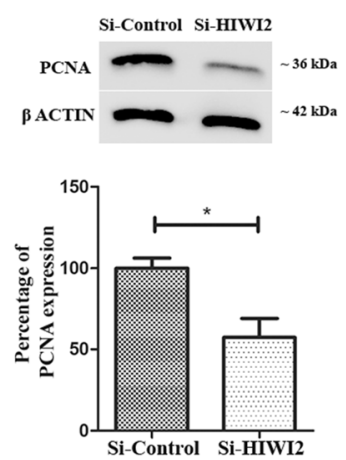

b

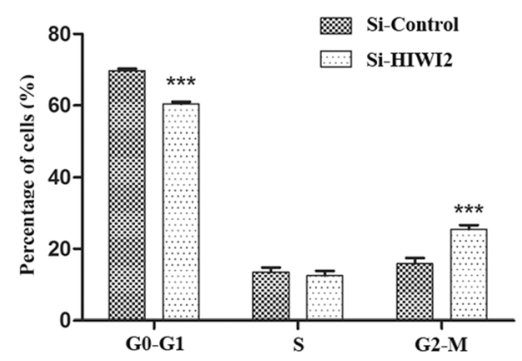

d
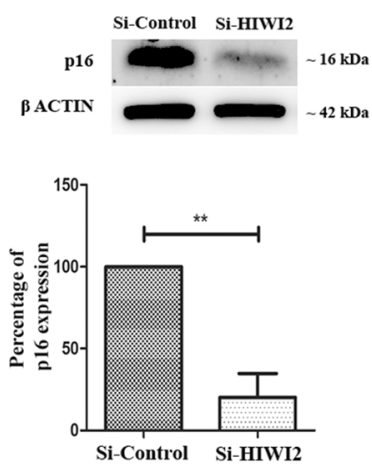

Fig. 3 HIWI2 silencing affects the proliferation of Y79 cells. a - Histogram shows the changes in the cell cycle distribution of Si-HIWI2 Y79 cells. $\mathbf{b}$ - Bar graph represents the percentage of cells distributed among various phases of the cell cycle in HIWI2 knockdown. c - Western blot showing the expression of PCNA upon HIWI2 knockdown in Y79 cells. Bar graph represents the percentage of PCNA expression. $\mathbf{d}$ - Western blot showing the expression of p16 upon HIWI2 knockdown in Y79 cells. The bar graph represents the percentage of p16 expression. Student's $t$-test was used for statistical analysis. ${ }^{*} p<0.05,{ }^{* *} p<0.01$ and ${ }^{* * *} p<0.001$ were considered as statistically significant 
cell cycle regulation and proliferation of Y79 cells has been investigated. Our results show that HIWI2 might play a significant role in the progression of RB.

The expression of PIWI-like proteins was earlier reported to be upregulated in various cancer conditions $[16,23]$ and was observed to increase with increasing tumor grades [24]. Wang et al. showed that the suppression of HIWI proteins reduces growth, invasion and migration in glioma cells [25]. Our study also shows an elevated expression of HIWI2 in Y79 cells. Though increased expression of HIWI2 is reported in cervical cancer tissues, Y79 showed higher expression of HIWI2 than the levels reported in cervical cancer cells [19]. This could be attributed to the cellular origin of cancer, which correlates with the finding from our previous study showing higher expression of PIWI-like proteins in the retina than in the retinal pigment epithelium (RPE) [11].

piRNAs, the small noncoding RNAs that bind to PIWI proteins, are also deregulated in cancerous conditions. The expression of piR651 significantly increases in non-small cell lung carcinoma [26] and piRNA823 is overexpressed in multiple myeloma patients [27]. Hence, it is possible that HIWI2-associated piRNAs might also be altered in RB and could play a role in the pathogenesis.

Recently, cancer stem cells (CSC) and markers have become a promising therapeutic target in various cancer types. For instance, the polycomb family protein BMI-1, designated as a stemness marker for CSC, is important for the self-renewal and tumor initiation of CSCs, and also for neural and hematopoietic stem cells. Interestingly, BMI-1 also targets the $\mathrm{p} 16^{\mathrm{INK4a}}$ gene to regulate various events of tumor progression [28]. Similarly, PIWI proteins, which are important for germline stem cell (GSC) selfrenewal [6], are also needed for continued proliferation of cancer cells [18]. Hence, we could speculate that PIWI-like proteins might be required for CSC self-renewal as well, which remains unexplored.

The stem cell-related genes in cancer cells could define the characteristics of CSCs. In Y79, the absence of HIWI2 deregulated OTX2, an eye field specification marker that is critical for the development of forebrain and eye [20]. OTX2 is crucial for cell fate determination and terminal differentiation of photoreceptors [29]. Deletion of otx2 in adult mouse retina causes rapid changes in RPE, and degeneration of the outer segments of photoreceptors [21]. otx2 gene mutations are associated with severe ocular malformations. This includes anopthalmia, micropthalmia, coloboma and other retinal dystrophy [30, 31]. Taken together, HIWI2 regulation on OTX2 indicates an important role for HIWI2 in human retinal physiology.

HIWI2 might regulate OTX2 either directly or indirectly through signalling pathways. In our previous report, we demonstrated the effects of HIWI2 silencing on the Akt pathway [11]. OTX2 is known to be activated by the PI3K/Akt signalling axis [32]. In addition, FGF2 increases the expression of OTX2 in precursor cells of mammalian telencephalon [33] and OTX2 is also known to regulate FGF8 and other FGF signalling responses in mice [34]. Interestingly, HIWI2 is also known to activate the FGF signalling pathway in breast cancer cells [14]. Perhaps, HIWI2 might regulate the expression of OTX2 either through PI3K/Akt or FGF signalling pathways.

VEGF and its receptor VEGFR2 are known to increase with invasiveness of RB [35]. Intriguingly, downregulating the expression of piRNA-823 reduces VEGF levels in multiple myeloma [27]. Our results show that the VEGFR2 is downregulated in RB cells on HIWI2 silencing. Moreover, bevacizumab, an anti-VEGF agent is known to inhibit the 
differentiation of RB cells [36]. OTX2 is also involved in inhibiting the differentiation of medulloblastoma cells [22]. Since the levels of both OTX2 and VEGFR2 are altered upon HIWI2 knockdown, it would be interesting to study whether HIWI2 affects the differentiation of RB cells.

We also observed that HIWI2 silencing arrests RB cells at the G2-M phase. However, it has been reported that loss of HIWI2 in HeLa did not show any difference in cell cycle distribution [19]. Therefore, the effects of HIWI2 on cell cycle distribution might be cell specific, as HIWI knockdown arrested gastric cancer cells at the G2-M stage, whereas glioma cells were arrested at the G0-G1 stage [25, 37].

In addition, a low level of PCNA in Y79 cells upon HIWI2 silencing suggested inhibition of proliferation. Besides, reduced expression of p16 in HIWI2 knockdown cells also indicated suppression of proliferation as it has been reported that downregulation of p16, hinders proliferation in cervical cancer cells [38]. Moreover, in RB patients, the p16 gene is found to be downregulated due to hypermethylation at the $\mathrm{p} 16^{\mathrm{INK} 4 \mathrm{a}}$ promoter region [3]. Since the PIWI/piRNA complex is an epigenetic activator, HIWI2 might have caused a reduction in the expression of p16 in Si-HIWI2 Y79 cells [39]. Nonetheless, determining whether HIWI2 has direct or secondary effects will require further study.

A recent report suggested OTX2 as a probable therapeutic target, since it decreases the tumor size and growth in RB xenografts [40]. In this study, we have shown the effect of HIWI2 in downregulating the expression of OTX2 in Y79. Other reports have shown the importance of HIWI2 in tumorigenesis and it has also been suggested as a biomarker in various cancer conditions [12]. Unravelling the exact molecular mechanism of HIWI2 in RB can determine its potential as a therapeutic target in the future.

\section{Conclusion}

We show that the PIWI-like protein HIWI2 is aberrantly expressed in retinoblastoma cells. Silencing HIWI2 arrests cell cycle probably through OTX2. This study provides novel insights into the possible crosstalk between HIWI2 and OTX2. Our results also point out that HIWI2 might play a crucial role in retinal pathophysiology. Further research could throw light on the potential of HIWI2 as a therapeutic target for retinoblastoma.

Abbreviations

ARPE19: Adult retinal pigment epithelial cells; CSC: Cancer stem cell; PCNA: Proliferating cell nuclear antigen; RB: Retinoblastoma; RPE: Retinal pigment epithelium

\footnotetext{
Acknowledgements

We would like to thank Dr. Suresh Rayala of the Indian Institute of Technology Madras for his generous gift of the p16 antibody.

Funding

We would like to acknowledge the financial assistance provided by the Department of Science and Technology as part of project SR/FT/LS-145/2010 and by the Department of Biotechnology as part of DBT-Neurobiology Taskforce project BT/PR5055/MED/30/761/2012. We would like to thank the Indian Council of Medical Research who supported us as part of project BMS/FW/BIOCHEM/2015-23270/OCT-2015/24/TN/PVT and Max Planck India mobility grant IGSTC/ MPG/FS(SC)2012. Subbulakshmi Chidambaram would like to acknowledge the University Grants Commission of New Delhi for the award of Assistant Professorship under its Faculty Recharge Program (UGC-FRP). The funding body was not involved in the design of the study, collection, analysis and interpretation of the data, or writing of the manuscript.
} 


\section{Authors' contributions}

SS designed and performed the experiments and wrote the manuscript. JPA and SC conceived the idea and reviewed the manuscript. Funding was obtained by SC. All authors read and approved the final manuscript.

\section{Ethics approval and consent to participate}

Not applicable.

\section{Consent for publication}

Not applicable.

\section{Competing interests}

The authors declare that they have no competing interests.

\section{Publisher's Note}

Springer Nature remains neutral with regard to jurisdictional claims in published maps and institutional affiliations.

\section{Author details}

${ }^{1}$ RS Mehta Jain Department of Biochemistry and Cell Biology, Vision Research Foundation, Chennai, India. ${ }^{2}$ School of Chemical and Biotechnology, SASTRA University, Thanjavur, India. ${ }^{3}$ SN ONGC Department of Genetics and Molecular Biology, Vision Research Foundation, Chennai, India. ${ }^{4}$ Central Inter-Disciplinary Research Facility (CIDRF), Sri Balaji Vidyapeeth University, Mahatma Gandhi Medical College and Research Institute Campus, Pondicherry, India.

${ }^{5}$ Department of Biochemistry and Molecular Biology, Pondicherry University, Puducherry, India.

Received: 10 May 2017 Accepted: 22 August 2017

Published online: 29 August 2017

\section{References}

1. Friend SH, Bernards R, Rogelj S, Weinberg RA, Rapaport JM, Albert DM, et al. A human DNA segment with properties of the gene that predisposes to retinoblastoma and osteosarcoma. Nature. 1986;323:643-6. doi: 10. 1038/323643a0.

2. Knudson AG. Mutation and cancer: statistical study of retinoblastoma. Proc Natl Acad Sci U S A. 1971;68:820-3. doi: 10.1073/pnas.68.4.820.

3. Indovina P, Acquaviva A, De Falco G, Rizzo V, Onnis A, Luzzi A, et al. Downregulation and aberrant promoter methylation of p16INK4A: a possible novel heritable susceptibility marker to retinoblastoma. J Cell Physiol. 2010; 223:143-50. doi: 10.1002/jcp.22019.

4. Dalgard CL, Van Quill KR, O'Brien JM. Evaluation of the in vitro and in vivo antitumor activity of histone deacetylase inhibitors for the therapy of retinoblastoma. Clin Cancer Res. 2008;14:3113-23. doi: 10.1158/1078-0432. CCR-07-4836.

5. Chintagumpala M, Chevez-Barrios P, Paysse EA, Plon SE, Hurwitz R. Retinoblastoma: review of current management. Oncologist. 2007;12:1237-46. doi: 10.1634/theoncologist.12-10-1237.

6. Cox DN, Chao A, Baker J, Chang L, Qiao D, Lin H. A novel class of evolutionarily conserved genes defined by piwi are essential for stem cell self-renewal. Genes Dev. 1998;12:3715-27. Available: http://www.ncbi.nlm.nih.gov/ pubmed/9851978

7. Girard A, Sachidanandam R, Hannon GJ, Carmell MA. A germline-specific class of small RNAs binds mammalian piwi proteins. Nature. 2006;442:199-202. doi: 10.1038/nature04917.

8. Xu M, You Y, Hunsicker P, Hori T, Small C, Griswold MD, et al. Mice deficient for a small cluster of piwi-interacting RNAs implicate piwi-interacting RNAs in transposon control. 2008;57: 51-57. doi:10.1095/biolreprod.108.068072.

9. Sasaki T, Shiohama A, Minoshima S, Shimizu N. Identification of eight members of the argonaute family in the human genome. Genomics. 2003;82:323-30. doi: 10.1016/50888-7543(03)00129-0.

10. Sugimoto K, Kage H, Aki N, Sano A, Kitagawa H, Nagase T, et al. The induction of H3K9 methylation by PIWIL4 at the p16Ink4a locus. Biochem Biophys Res Commun. 2007;359:497-502. doi: 10.1016/j.bbrc.2007.05.136.

11. Sivagurunathan S, Palanisamy K, Arunachalam JP, Chidambaram S. Possible role of HIWI2 in modulating tight junction proteins in retinal pigment epithelial cells through Akt signaling pathway. Mol Cell Biochem. 2017;427: 145-56. doi: 10.1007/s11010-016-2906-8.

12. Tan Y, Liu L, Liao M, Zhang C, Hu S, Zou M, et al. Emerging roles for PIWI proteins in cancer. 2015;47: 315-324. doi:10.1093/abbs/gmv018.

13. Lu Y, Zhang K, Li C, Yao Y, Tao D, Liu Y, et al. Piwil2 suppresses P53 by inducing phosphorylation of signal transducer and activator of transcription 3 in tumor cells. PLoS One. 2012;7:1-8. doi: 10.1371/journal.pone.0030999.

14. Wang Z, Liu N, Shi S, Liu S, Lin H. The role of PIWIL4, an argonaute family protein, in breast cancer. J Biol Chem. 2016;291:10646-58. doi: 10.1074/jbc.M116.723239.

15. Krishnan P, Ghosh S, Graham K, Mackey JR, Kovalchuk O, Damaraju S. Piwi-interacting RNAs and PIWI genes as novel prognostic markers for breast cancer. Oncotarget. 2014;7:37944-56. 10.18632/oncotarget.9272.

16. Wang Y, Liu Y, Shen X, Zhang X, Chen X, Yang C, et al. The PIWI protein acts as a predictive marker for human gastric cancer. Int J Clin Exp Pathol. 2012;5:315-25. Available: http://www.pubmedcentral.nih.gov/articlerender. fcgi?artid $=3365820 \&$ tool=pmcentrez\&rendertype $=$ abstract

17. Bao B, Ahmad A, Azmi AS, Ali S, Sarkar FH. Overview of cancer stem cells (CSCs) and mechanisms of their regulation: implications for cancer therapy. Current protocols in pharmacology. Hoboken: Wiley; 2013. doi: 10. 1002/0471141755.ph1425s61.

18. Juliano C, Wang J, Lin H. Uniting germline and stem cells : the function of piwi proteins and the piRNA pathway in diverse organisms; 2011. doi: 10.1146/annurev-genet-110410-132541. 
19. Su C, Ren Z-J, Wang F, Liu M, Li X, Tang H. PIWIL4 regulates cervical cancer cell line growth and is involved in downregulating the expression of p14ARF and p53. FEBS Lett. 2012;586:1356-62. doi: 10.1016/j.febslet.2012.03.053.

20. Martinez-Morales JR, Signore M, Acampora D, Simeone A, Bovolenta P. Otx genes are required for tissue specification in the developing eye. Development. 2001;128:2019-30. Available: http://www.ncbi.nlm.nih.gov/ pubmed/11493524

21. Béby F, Housset M, Fossat N, Le Greneur C, Flamant F, Godement P, et al. Otx2 gene deletion in adult mouse retina induces rapid RPE dystrophy and slow photoreceptor degeneration. Reh TA, editor. PLoS One. 2010;5: e11673. doi: 10.1371/journal.pone.0011673.

22. Bunt J, Hasselt NE, Zwijnenburg DA, Hamdi M, Koster J, Versteeg R, et al. OTX2 directly activates cell cycle genes and inhibits differentiation in medulloblastoma cells. Int J Cancer. 2012;131:E21-32. doi: 10.1002/ijc.26474.

23. Lee JH, Schütte D, Wulf G, Füzesi L, Radzun HJ, Schweyer S, et al. Stem-cell protein Piwil2 is widely expressed in tumors and inhibits apoptosis through activation of Stat3/BCl-XL pathway. Hum Mol Genet. 2006;15:201-11. doi: 10.1093/hmg/ddi430.

24. Sun G, Wang Y, Sun L, Luo H, Liu N, Fu Z, et al. Clinical significance of Hiwi gene expression in gliomas. Brain Res Elsevier BV. 2010;1373:183-8. doi: 10.1016/.jbrainres.2010.11.097.

25. Wang X, Tong X, Gao H, Yan X, Xu X, Sun S, et al. Silencing HIWI suppresses the growth, invasion and migration of glioma cells. Int J Oncol. 2014;45:2385-92. doi: 10.3892/ijo.2014.2673.

26. Li D, Luo Y, Gao Y, Yang Y, Wang Y, Xu Y, et al. piR-651 promotes tumor formation in non-small cell lung carcinoma through the upregulation of cyclin D1 and CDK4. Int J Mol Med. 2016;38:927-36. doi: 10.3892/ijmm. 2016.2671.

27. Yan H, Wu Q-L, Sun C-Y, Ai L-S, Deng J, Zhang L, et al. piRNA-823 contributes to tumorigenesis by regulating de novo DNA methylation and angiogenesis in multiple myeloma. Leukemia. 2015;29:196-206. doi: 10.1038/leu.2014.135.

28. Wang M-C, Li C-L, Cui J, Jiao M, Wu T, Jing LI, et al. BMI-1, a promising therapeutic target for human cancer. Oncol Lett Spandidos Publications. 2015;10:583-8. doi: 10.3892/ol.2015.3361.

29. Koike C, Nishida A, Ueno S, Saito H, Sanuki R, Sato S, et al. Functional roles of Otx2 transcription factor in postnatal mouse retinal development. Mol Cell Biol. 2007;27:8318-29. doi: 10.1128/MCB.01209-07.

30. Ragge NK, Brown AG, Poloschek CM, Lorenz B, Henderson RA, Clarke MP, et al. Heterozygous mutations of OTX2 cause severe ocular malformations. Am J Hum Genet. 2005;76:1008-22. doi: 10.1086/430721.

31. Wyatt A, Bakrania P, Bunyan DJ, Osborne RJ, Crolla JA, Salt A, et al. Novel heterozygous OTX2 mutations and whole gene deletions in anophthalmia, microphthalmia and coloboma. Hum Mutat. 2008;29:E278-83. doi: 10. 1002/humu.20869.

32. Peng $Y$, Jiang $B-H$, Yang $P-H$, Cao Z, Shi $X$, Lin MCM, et al. Phosphatidylinositol 3-kinase signaling is involved in neurogenesis during Xenopus embryonic development. J Biol Chem. 2004;279:28509-14. doi: 10.1074/jbc. M402294200.

33. Robel L, Ding M, James AJ, Lin X, Simeone A, Leckman JF, et al. Fibroblast growth factor 2 increases Otx2 expression in precursor cells from mammalian telencephalon. J Neurosci. 1995;15:7879-91. Available: http://www. ncbi.nlm.nih.gov/pubmed/8613727

34. Hoch RV, Lindtner S, Price JD, Rubenstein JLR. OTX2 transcription factor controls regional patterning within the medial ganglionic eminence and regional identity of the septum. Cell Rep. 2015;12:482-94. doi: 10.1016/..celrep.2015.06.043.

35. Garcia JR, Gombos DS, Prospero CM, Ganapathy A, Penland RL, Chévez-Barrios P. Expression of angiogenic factors in invasive retinoblastoma tumors is associated with increase in tumor cells expressing stem cell marker Sox2. Arch Pathol Lab Med. 2015;139:1531-8. doi: 10.5858/arpa.2014-0262-OA.

36. Heo JW, Kim JH, Cho CS, Jun HO, Kim DH, Yu YS, et al. Inhibitory activity of bevacizumab to differentiation of retinoblastoma cells. Means RE, editor. PLoS One. 2012;7:e33456. doi: 10.1371/journal.pone.0033456.

37. Liu X, Sun Y, Guo J, Ma H, Li J, Dong B, et al. Expression of hiwi gene in human gastric cancer was associated with proliferation of cancer cells. Int J Cancer. 2006;118:1922-9. doi: 10.1002/ijc.21575.

38. Zhang C, WEl B, Wang L. Downregulation of p16 ink4a inhibits cell proliferation and induces G1 cell cycle arrest in cervical cancer cells; 2014. p. 1577-85. doi: 10.3892/ijmm.2014.1731.

39. Yin $\mathrm{H}$, Lin $\mathrm{H}$. An epigenetic activation role of piwi and a piwi-associated piRNA in drosophila melanogaster. Nature. 2007:450:304-8. doi: 10.1038/nature06263.

40. Li J, Di C, Jing J, Di Q, Nakhla J, Adamson D. OTX2 is a therapeutic target for retinoblastoma and may function as a common factor between C-MYC, CRX, and phosphorylated RB pathways. Int J Oncol. 2015;47:1703-10. doi: 10. 3892/ijo.2015.3179.

\section{Submit your next manuscript to BioMed Central and we will help you at every step:}

- We accept pre-submission inquiries

- Our selector tool helps you to find the most relevant journal

- We provide round the clock customer support

- Convenient online submission

- Thorough peer review

- Inclusion in PubMed and all major indexing services

- Maximum visibility for your research

Submit your manuscript at www.biomedcentral.com/submit 